\title{
Formação e transições laborais em enfermagem: efeitos na identidade e no desenvolvimento profissional
}

\section{Training and work transition in nursing: effects on profesional identity and}

\section{development}

\author{
Rita Fernandes*, Beatriz Araújo**, Fátima Pereira*** \\ *Centro Hospitalar São João, ***Universidade Católica Portuguesa, Centro de Investigação Interdisciplinar em Saúde, \\ ***Faculdade de Psicologia e Ciências da Educação da Universidade do Porto
}

\begin{abstract}
Resumo
As alterações na sociedade refletem-se na formação, na profissão e no trabalho dos enfermeiros, originando novas profissionalidades. Neste estudo, de paradigma qualitativo, pretendeu-se conhecer as implicações da formação nas transições no mundo de trabalho, na identidade e no desenvolvimento profissional dos enfermeiros. Aplicou-se o Inventário de Identidade Psicossocial. A valorização da formação formal e informal nas transições laborais, permite a (re)construção de identidades baseadas na praticidade científica, na evolução dos saberes, integrada nos projetos profissionais, na partilha de conhecimentos e experiências entre pares e interprofissionais e no estabelecimento de referências para o desenvolvimento e aperfeiçoamento dos cuidados de enfermagem.
\end{abstract}

Palavras-chave: transições, trabalho, formação, identidade, desenvolvimento.

\begin{abstract}
The changes in society are reflected in the training, the profession and the work of the nurses, giving rise to new professionalism. In this study, a qualitative paradigm was intended to know the implications of training in transitions in the world of work, in the identity and professional development of nurses. The Psychosocial Identity Inventory was applied. In this study, a qualitative paradigm was intended to know the implications of training in transitions in the world of work, in the identity and professional development of nurses. The Psychosocial Identity Inventory was applied. The valorisation of formal and informal training in work transitions allows the (re)construction of identities based on scientific practicality, on the evolution of knowledge, integrated into professional projects, on the sharing of knowledge and experiences among peers and interprofessionals, and on the establishment of references for the development and improvement of nursing care.

Keywords:transitions, work, training, identity, development.
\end{abstract}

\section{Formação e transições laborais}

A formação, a profissão e o trabalho alteraram-se com as mudanças sociais modificando-se e transformando o sujeito social numa "ação individual e coletiva, da pessoa humana que, a partir de um leque de oportunidades em aberto, é capaz de construir o seu próprio caminho, construindo modos de emancipação social do trabalho que permitam a atualização de todas as potencialidades do ser humano." (Canário, 2016, p. 276), ao proporcionar diferentes articulações entre o trabalho e a aprendizagem. Sendo referido por Abreu (2001) que "o espaço de trabalho confunde-se com o espaço da formação" (p.20), com um papel de socialização e qualificação para a profissão de enfermeiros na formação inicial, permitindo a transição para o mundo do trabalho. Todavia, as influências da formação não se esgotam neste período; esta relação de influência da formatividade prolonga-se ao longo do seu desenvolvimento como profissional, com formações formais (pós-graduações, formação contínua em serviço) e com a formação informal.

Neste sentido, pretende-se conhecer as implicações da formação nas transições no mundo de trabalho na identidade e no desenvolvimento profissional dos enfermeiros.

No estudo das identidades com recurso à vertente biográfica e relacional de Dubar (1997), associada à vertente psicossocial de Zavalloni e Louis Guérin (1984), está implicada uma abordagem contextual, integrativa de diversos fenómenos que interferem nas (re)configurações identitárias, desde a formação ao trabalho, integrando as mudanças nos contextos socio-político-económicos.

$\mathrm{O}$ ensino de enfermagem, antes da entrada no Ensino Superior, baseava-se numa lógica de aprendizagem escolarizada e tradicional, não se inserindo esta temática neste estudo numa ação pejorativa desta modalidade de formação, mas usando o sentido crítico numa contextualização histórica das diversas formas de conceber a formação e o trabalho em enfermagem, ao longo dos anos, incidindo nos 5 anos anteriores à entrada no Ensino Superior até à atualidade.

Segundo Mestrinho (2011), os modelos de formação em que os professores de enfermagem baseavam o trabalho, seguia uma lógica profissionalizante, escolarizada e enraizada numa racionalidade técnica, sendo o modelo aplicacionista, gradualmente, substituído pelo modelo construtivista. Amendoeira (2009) refere que atualmente as Escolas Superiores de Enfermagem/Saúde se encontram num percurso 
transicional constrangido por elementos sociais e políticos, percurso esse necessário numa transição de formação, não só no $1^{\circ}$ ciclo, mas também no $2^{\circ}$ e $3^{\circ}$ ciclo, para preparar enfermeiros interventivos em contextos diferenciados e complexos.

Estas formas de ensinar e de conceber a formação desencadearam construções identitárias interligadas com os conceitos do estatuto de aluno congruentes com estes modelos, com implicações nas transições no mundo do trabalho dos enfermeiros, na identidade e no desenvolvimento profissional.

\section{Método}

Estudo descritivo transversal, de natureza qualitativa, baseado na Teoria Ego-ecológica de Zavalloni.

\section{Participantes}

A amostra não probabilística por redes é constituída por 19 enfermeiros, com uma média de idades de 40 anos e com um tempo de serviço de 17,8 anos, sendo um grupo relativamente homogéneo no que respeita à sua formação inicial e ao início da sua atividade profissional com um limite de 5 anos anteriores e os 10 anos posteriores à entrada do Ensino de Enfermagem no Ensino Superior, em 1988. Quanto à formação pós-graduada, 4 enfermeiros obtiveram pós-graduações, 5 especializações em Enfermagem e 4 mestrados. Considerando as evoluções na formação inicial, desde o grau de bacharel até à aquisição de grau licenciatura, seja através do Curso de Complemento de Formação em Enfermagem, seja de Curso de Licenciatura em Enfermagem, ou de Pós-Graduações, desde as Especializações em Enfermagem aos Mestrados de natureza profissional e académica. Estas características pessoais e contextuais proporcionam particularidades ao nível identitário e social, permitindo conhecer as diversas transições que a formação promoveu nas trajetórias profissionais destes enfermeiros, especificamente no desenvolvimento e na identidade profissional, percebendo as suas motivações e implicações com a formatividade.

\section{Instrumentos}

Utilizaram-se como instrumentos de recolha de dados o Inventário da Identidade Psicossocial (IIP) de Zavalloni e Louis-Guérin (1984) adaptado por Marta, Lopes, Pereira e Leite (2014), acrescentando os dados sociodemográficos, a técnica de Análise de Redes Associativas e uma súmula de questões em forma de entrevista estruturada.

\section{Procedimentos}

Após preenchimento do IIP pelos entrevistados, seguindo, as instruções do Método de Contextualização Representacional e com a recolha dos dados sociodemográficos, realizaram-se outros momentos de contacto e recolha de dados com a realização da Técnica de Redes Associativa aliada a uma pequena súmula de questões em forma de entrevista estruturada, quando julgado necessário. Foram seguidos todos os procedimentos éticos, desde a divulgação da informação de forma oral e redigida da finalidade e dos objetivos da pesquisa, tal como a autorização por escrito da gravação e das entrevistas. As transcrições foram devolvidas aos participantes e foi dada a possibilidade de as alterarem.

Posteriormente, realizou-se a análise de conteúdo segundo Bardin (2010), com a construção de categorias e subcategorias.

\section{Resultados}

Da análise dos dados emergiram as categorias denominadas de: tipos de formação e valorização da formação.

\section{Tipos de formação}

As formações mencionadas pelos enfermeiros participantes foram a formação formal, ou seja, a formação inicial de enfermagem (bacharelato e/ou licenciatura), a formação pós-graduada (pós-graduações, pós-licenciaturas, mestrados profissionais e académicos e doutoramento), a formação em serviço e a formação contínua informal.

Formação inicial. Os enfermeiros referiram que o paradigma tradicional na formação inicial os formou nas competências científicas, técnicas e relacionais, nas atualizações de conhecimentos, mas não no desenvolvimento do pensamento crítico, com dificuldades acrescidas na confrontação de uma identidade "virtual" a uma identidade "real", na transição para o mundo do trabalho e com implicações na (re)construção identitária.

Formação pós-graduada. Com a formação pósgraduada, alguns enfermeiros puderam contactar com o novo paradigma da formação vigente, considerando a integração experiencial no desenvolvimento das competências profissionais especializadas, mas também nas competências crítico-reflexivas, que lhes permitiram (re)construir e identificar-se com uma identidade profissional mais autónoma e significativa. A formação Pós-Graduada, também, foi visualizada como estratégia de desenvolvimento profissional e negociação identitária, com a passagem de uma visão de profissão que valorizava mais as atividades interdependentes para a visão de uma profissão com maiores possibilidades de autonomia profissional e de participação no desenvolvimento profissional de outros enfermeiros.

Apesar destes efeitos positivos serem referidos pela maioria, alguns definem esta formação como dispendiosa, pouco flexível, sem apoios, sendo por vezes referidos entraves pelos enfermeiros-chefes, e sem reconhecimento monetário ou social.

Formação em serviço. A importância da formatividade denota-se na formação contínua, quer pela exigência da complexidade de atuação, quer pelo dever profissional, no entanto, é dificultada pelas medidas economicistas e pela tendência escolarizada e transmissiva destes contextos. Os entrevistados consideram a formação em serviço como oportunidade de partilha e desenvolvimento profissional, mas também referem outras fragilidades na formação em serviço, como a reduzida quantidade de formações, a pouca adesão por parte dos enfermeiros e a existência de momentos organizados e planeados de formação, mas 
nem sempre concretizados por razões economicistas e défices de recursos humanos. As estruturas de formação institucionais referidas são: a Administração Regional de Saúde (ARS) nos cuidados de saúde primários, assinalada como local situado longe dos contextos de trabalho e com oferta formativa insuficiente, e os Departamentos de Formação Permanente (DEP) nos cuidados diferenciados, caraterizados por formações universais e repetitivas para todos os enfermeiros da instituição, sem atender às especificidades dos formandos e dos contextos, com insuficiente divulgação, sendo que as formações ministradas são designadas como desinteressantes e, por uma entrevistada, até como desatualizadas.

Formação contínua. A formação informal foi percecionada como um espaço de formação contínua alternativa que permite a partilha e o desenvolvimento de perícia clínica, num processo supervisivo colaborativo em que a liderança se destaca como mediador desta formatividade. A formação informal é percecionada como momento de reflexão individual e em grupo e preponderante na formação de colegas e na própria formação, quer numa tentativa de colmatar dificuldades em grupo, quer inserida no quotidiano profissional como parte integrante do exercício profissional. Apesar da formação contínua estar inserida numa conceção teórica de formação informal, alguns enfermeiros pretendem o controlo desta formação como estratégia de intensificação e proliferação desta valência formativa.

\section{Valorização da formação}

A formação profissional dos enfermeiros é valorizada quando contribui para o desenvolvimento profissional, articula a teoria e a prática, adequa-se ao projeto profissional, capacita para o estabelecimento de referências para os pares, prima pela organização e possibilita a partilha de conhecimentos.

Desenvolvimento profissional. $O$ desenvolvimento profissional encontra-se profundamente ligado à identidade profissional destes enfermeiros, que percecionam a evolução nos saberes de enfermagem e dos cuidados, ao longo do seu percurso, com implicações identitárias profissionais.

Articulação entre a teoria e a prática. Os entrevistados desejam a articulação entre a teoria e a prática na sua formação, mas valorizam os conhecimentos que estejam diretamente envolvidos com a sua prática profissional, na procura de uma teoriaprática.

Correspondência com projeto profissional em desenvolvimento. A formação para ser significativa para estes profissionais de enfermagem não pode ser imposta, deve partir da vontade e de um entusiasmo que corresponda ao seu projeto profissional em desenvolvimento, sem receio de recorrer a outras áreas de formação, com o intuito de enriquecer como profissional.

Organização da formação. Os enfermeiros participantes valorizam a organização da formação de um modo rigoroso e possível de controlar, admitindo até a necessidade deste mesmo controlo na formação informal.
Partilha de conhecimentos. Outra valorização da formação prende-se com a partilha de experiências e conhecimentos entre pares e outros profissionais, para o desenvolvimento e aperfeiçoamento dos cuidados de enfermagem.

Existência de referências. $O$ anseio por serem considerados referências para os seus pares, foi uma das caraterísticas valorizadas, nas formações formal e informal, por estes enfermeiros.

\section{Discussão}

As formações formal e informal, nos diversos contextos formativos, foram claramente valorizadas por estes profissionais, apresentando pontos fortes e fragilidades. Estas formações poderão ser transformadas e aperfeiçoadas, ao considerarem-se as experiências formativas e de trabalho dos formandos, tais como as suas expetativas e representações.

Os enfermeiros entrevistados referem que, na formação inicial, não desenvolveram o sentido crítico, mas apenas a forma de atualizar conhecimentos e que as competências adquiridas não foram integradas profissionalmente, exigindo-se no percurso profissional a (re)construção dessas competências. As fragilidades de um ensino tradicional, de uma relação distante entre professor-aluno, com uma avaliação de caráter ameaçador, são apontadas à formação inicial e prendemse com os modelos de formação seguidos. No entanto, os enfermeiros percecionam algumas mudanças no ensino de enfermagem, com o retorno aos espaços escolares para realização de pós-graduações.

Com a entrada das Escolas de Enfermagem no Ensino Superior e com a exigência do Processo de Bolonha, os paradigmas de formação baseiam-se em modelos construtivistas e no desenvolvimento da autonomia nos estudantes. As pós-graduações dos enfermeiros entrevistados decorreram ao longo destas mudanças, na formação formal.

Em relação a esta transformação do Ensino Superior, com a aplicação desta diretiva europeia, a preocupação nas Escolas Superiores de Enfermagem desenrola-se, não só com o desenvolvimento de diversas competências científicas, técnicas e relacionais, mas essencialmente na área das competências reflexivas e do pensamento crítico numa aprendizagem que transcende o espaço escolar (Dotta, Marta, Ferreira \& Diogo, 2013).

$\mathrm{Na}$ formação pós-graduada, os enfermeiros fazem referência às transformações a que foram sujeitos, na articulação dos seus saberes experienciais com a teoria que estes contextos formativos ofereceram no desenvolvimento das competências já trabalhadas nos contextos de trabalho e interligadas com a formação pósgraduada permitindo o aperfeiçoamento a o desenvolvimento de outras, ao encadear os diversos saberes na sua trajetória como profissionais e no aperfeiçoamento do pensamento crítico.

Serra (2011) refere que o desenvolvimento da identidade e dos valores profissionais ocorre num processo de socialização formal e informal iniciado na formação inicial e alvo de reformulações na trajetória profissional. 
A profissão de enfermagem, também, foi alvo de mudança de paradigma que desencadeou reformulações no seu ensino, por isso também se veiculou na formação inicial de alguns destes enfermeiros a maior preocupação com as vertentes técnica e científica, num enquadramento legal da profissão. Posteriormente, modificando a sua relevância para uma identidade autónoma e interprofissional composta pelo cuidar e pelo tratar, numa perspetiva holística da pessoa e de empowerment do indivíduo e das populações (Collièrre, 1999).

Com a análise dos dados das entrevistas, verificou-se que tanto os modelos de formação utilizados, como a representação da profissão dos cuidados de enfermagem veiculados influenciaram a identidade profissional

Estes reconhecem que, apesar de terem que realizar aquisições e reformulações nas competências no mundo profissional, por vezes distantes do mundo da escola, as configurações identitárias foram reconstruídas, mas tiveram como base estrutural a formação inicial.

Abreu (2001) menciona que, na formação inicial, os enfermeiros se desenvolvem num processo de socialização, nomeadamente no primeiro contato com a profissão que decorre na formação clínica, representando espaços e momentos importantes para construir representações, evidenciando os contextos de trabalho na atribuição das significações da profissionalidade do enfermeiro: "no sentido em que estes estão dependentes de uma dinâmica cognitiva e avaliativa definida em contexto, em contato com um conjunto de fatores materiais, relacionais e simbólicos inerentes ao funcionamento duma organização de saúde.” (p. 81).

Pereira e Lima (2013) referem que, no processo de integração à profissão, o estudante e o enfermeiro, que deu entrada no mundo do trabalho, confrontam-se com "a enfermagem que é ensinada (enfermagem ideal) e com a enfermagem praticada (enfermagem real), o que pode constituir um desafio à sua iniciativa e à sua capacidade de adaptação." (p.103), ou o que Dubar (1997) designa o confronto entre identidades "virtuais" veiculadas pela escola e as identidades "reais" do contexto profissional, desencadeando continuidades ou ruturas entre identidade "herdada" e a identidade "visada".

Os enfermeiros entrevistados descrevem esta passagem idealizada da profissão a uma passagem mais contextualizada com a prática como consternadora e complexa, mas necessária à sua identidade profissional, tendo de abandonar ideias, mas abraçando outras e até interligando representações, construindo uma identidade profissional particular e de realização no seu quotidiano profissional. $\mathrm{Na}$ formação inicial, predominou a apetência e a valorização das atividades interdependentes e, em alguns casos, o caráter psicosocial. Com as experiências profissionais aliadas a formações pósgraduadas adquiriu-se a possibilidade de uma maior autonomia profissional que alia as atividades de natureza interdependentes e as de natureza independentes, conseguindo nas duas vertentes uma construção identitária na conquista da autonomia profissional. No entanto, as fragilidades, apontadas pelos entrevistados, desta formação pós-graduada prendem-se com fatores sociais e económicos que dificultam o acesso e a frequência desta formação formal dos enfermeiros.
Todavia estes enfermeiros sentem-se impelidos a participar no seu desenvolvimento profissional e no dos seus pares.

O desenvolvimento e a identidade profissional constroem-se na formação inicial com as influências dos formadores - professores e enfermeiros - dos paradigmas de formação e ensino e dos contextos profissionais e sociais; ainda assim, este processo não termina neste período, ele prolonga-se ao longo da vida profissional na articulação das experiências com as formações formal e informal.

Os contextos de trabalho e o grau de complexidade funcional dos enfermeiros exigem transformações e atualizações constantes, daí a formação contínua no serviço se tornar importante nesse processo. No trabalho, surgem imprevisibilidades e especificidades nas atuações profissionais que, segundo Lopes (2001), exigem articulação dos recursos cognitivos formais e informais que são adquiridos na formação.

$\mathrm{Na}$ carreira de enfermagem e no código deontológico profissional dos enfermeiros, está comtemplada a formação contínua e permanente. Atualmente, pelos discursos da maioria dos entrevistados, estas formações encontram-se quase em extinção nos serviços de forma formal, constatando-se a obrigatoriedade e a massificação da formação nas estruturas de formação institucionais; esse facto resulta em desvalorização e não adesão a estas formas de formação pelos enfermeiros.

O modelo escolar transmissivo e expositivo é o eleito pelos enfermeiros responsáveis pela formação em serviço formal e planeada (D’Espiney, 2003), não considerando os enfermeiros ativos no seu processo formativo. Os enfermeiros participantes referem que nos seus locais de trabalho existem planos de formação anuais adaptados face às necessidades detetadas e aos défices de recursos humanos. As formações tornam-se assim reduzidas, pontuais e sem interligação, dificultando o que Canário (2003) designa de ação transformadora da formação contínua.

As competências reflexivas que não foram exploradas na formação inicial destes enfermeiros, continuam a não ser desenvolvidas pelas estruturas de formação contínua formal nos serviços e instituições, não considerando o seu papel ativo, nem a sua experiência e perícia.

A grande maioria dos enfermeiros entrevistados privilegia e aprecia a formação contínua informal. Os entrevistados referem esta formação informal nos seus contextos de trabalho, quer numa relação que Garrido, Simões e Pires (2008) definem de supervisão clínica entre um enfermeiro experiente e outro menos experiente, quer numa parceria designada por Gottlieb, Gottlieb e Shamian (2012) como colaborativa com outro enfermeiro considerado par.

Segundo Alarcão e Canha (2013) a supervisão numa forma tradicional resulta de uma relação hierarquizada e verticalizada entre os atores, enquanto a colaboração se baseia numa relação democrática e horizontal; na junção destes dois conceitos aparentemente contraditórios surge a supervisão colaborativa.

A formação informal é percecionada pelos enfermeiros entrevistados como momento de reflexão individual e em conjunto, deveras importante na formação de colegas e 
na própria formação, numa tentativa de colmatar dificuldades em grupo, assim como inserida no quotidiano profissional, como parte integrante do exercício profissional.

O desafio na formação destes enfermeiros destaca-se quando estes centram a valorização da formação num controlo organizativo do processo, originando conflitos na planificação e estruturação de toda a formação, inclusive a informal. Denotando que, apesar de teoricamente conceberem a formação informal, sentem dificuldades na sua concretização de forma informal, decorrente da incorporação duma formatividade escolarizada, o que converge com dificuldades identificadas em Macedo, Pinheiro e Costa (2014). Os enfermeiros manifestam o desejo de controlo da formação informal como estratégia de intensificação e proliferação desta valência formativa, reconhecendo a importância desta formação no seu percurso profissional, mas desvirtualizando-a da sua informalidade.

Macedo et al. (2014) salientam a necessidade de, nesta relação de colaboração, se enquadrarem os peritos líderes clínicos - envolvidos em processos denominados de crítico-reflexivos por Wilson (2014), num continuum de desenvolvimento profissional progressivo e (re)construção identitária entre pares.

A importância das referências entre pares (líderes clínicos) no desenvolvimento profissional e identitário, também, foi considerada na valorização da formação; os entrevistados reconhecendo-a desejam, também, serem referência para os outros, que almejam concretizar com a recursividade das formações - formal e informal - e da prática clínica, num ambiente colaborativo e valorizador de $\mathrm{Si}$ como pessoa e profissional.

\section{Conclusão}

A formação formal destes profissionais ocorreu em épocas de transições da própria formação, como: a entrada do Ensino de Enfermagem para o Ensino Superior, fortemente marcada pela lógica profissionalizante e escolarizada; e, num espaço temporal mais recente, num enquadramento do ensino ao nível europeu, com o Processo de Bolonha, com a integração da autonomia do sujeito social e profissional. A mudança de paradigmas de formação desencadeou transições no desenvolvimento e nas identidades profissionais.

A importância da formatividade denota-se na formação contínua, quer pela exigência da complexidade de atuação, quer pelo dever profissional, no entanto, é dificultada pelas medidas economicistas e pela tendência escolarizada e transmissiva destes contextos. A formação informal foi percecionada como um espaço de formação contínua alternativa que permite a partilha e o desenvolvimento de perícia clínica, num processo supervisivo colaborativo em que a liderança se destaca como mediador desta formatividade.

A valorização da formação nas transições no trabalho por estes profissionais, revela uma profissionalidade baseada numa praticidade científica, em que a formatividade formal e informal se destaca num clima colaborativo, indo ao encontro dos seus interesses e experiências, enquadrados no seu projeto profissional e numa visão de desenvolvimento que compreende a interprofissionalidade.

\section{Referências}

Abreu, W. C. (2001). Identidades, formação e trabalho: das culturas locais às estratégias identitárias dos enfermeiros. Coimbra: Formasau.

Alarcão, I. \& Canha, B. (2013). Supervisão e colaboração: uma relação para o desenvolvimento. Porto: Porto Editora.

Amendoeira, J. (2009). Ensino de Enfermagem. Perspetivas de desenvolvimento. Pensar Enfermagem. $N^{\circ} 1$, Vol. 13, 3-12. ISSN 0873-8904. http://pensarenfermagem.esel.pt/pe/index.asp?accao $=\mathrm{s}$ howeditorial\&id revista $=7$

Bardin, L. (2010). Análise de conteúdo. $5^{\mathrm{a}}$ ed. Lisboa: Edições 70.

Canário, R. (2003). Formação e situações de trabalho. Porto: Porto editora

Canário, R. (2016). Trabalho e formação de adultos: entre o ser e o ter. Revista Contemporânea de Educação, Vol. 11, $N^{o}$ 22, pp. 264-280. http://doi:http://dx.doi.org/10.20500/rce.v11i22.2700.

Colliére, M. F. (1999). Promover a vida: da prática das mulheres de virtude aos cuidados de enfermagem. Lisboa: Lidel - Edições Técnicas e Sindicato dos Enfermeiros Portugueses.

D’Espiney, L. (2003). Formação inicial / Formação contínua de enfermeiros: uma experiência de articulação em contexto de trabalho. (2 $2^{\mathrm{a}}$ ed.) Em R. Canário (Ed.). Formação e situações de trabalho (pp.169-188). Porto: Porto Editora.

Dotta, L. T., Marta, M., Ferreira, E. \& Diogo, F. (2013). $\mathrm{O}$ desenvolvimento da autonomia nos processos de formação de estudantes da Enfermagem e do Ensino. Em Amélia Lopes (Ed.) Formação inicial de professores e de enfermeiros: identidades e ambientes (pp. 153-167). Porto: Livpsic.

Dubar, C. (1997). A Socialização: construção das identidades sociais e profissionais. Porto: Porto Editora.

Garrido, A., Simões, J. \& Pires, R. (2008). Supervisão clínica em enfermagem perspetivas práticas. Aveiro: Universidade de Aveiro, Comissão Editorial.

Gottlieb, L., Gottlieb, B., \& Shamian, J. (2012). Principles of strengths-based nursing leadership for strengths-based nursing care: a new paradigm for nursing and healthcare for the 21 st century. Nursing Leadership. $\quad N^{\circ} 25, \quad$ Vol. 2, 38-50, https://doi.org/10.12927/cjnl.2012.22960

Lopes, A. (2001). Libertar o desejo resgatar a inovação - A construção de identidades profissionais em docentes. Lisboa: Instituto de Inovação Educacional.

Marta, M., Lopes, A., Pereira, F. \& Leite, M. (2014). A relevância profissional da formação de professores e enfermeiros no ensino superior: uma análise a partir das identidades dos formadores. Revista Lusófona de Educação, Vol. 27, $\mathrm{N}^{\mathrm{o}}$ 27, pp. 75-91. http://revistas.ulusofona.pt/index.php/rleducacao/articl e/view/4831. 
Macedo, A. P., Pinheiro, G.\& Costa, N. (2014). Supervisão colaborativa e desenvolvimento profissional em enfermagem. Revista de Enfermagem Referência, Série IV, $N^{o}$ 2, pp. 101-109. http://dx.doi.org/10.12707/RIII1381.

Mestrinho, M. G. (2011). Profissionalismo $e$ competências dos professores de enfermagem. Tese de Doutoramento em Educação. Universidade de LisboaInstituto de Educação, Lisboa, Portugal. http://repositorio.ul.pt/handle/10451/4227

Pereira, F. \& Lima, I. (2013). O contexto de formação inicial de enfermeiros na atualidade. Em Amélia Lopes (Ed.) Formação inicial de professores $e$ de enfermeiros: identidades e ambientes (pp. 91-108). Porto: Livpsic.

Serra, M. N. (2012). Aprender a ser enfermeiro: a construção identitária profissional por estudantes de enfermagem. Tese de Doutoramento em Educação, Instituto de Educação, Universidade de Lisboa, Lisboa, Portugal. http://repositorio.ul.pt/handle/10451/6025.

Zavalloni, M., Louis-Guérin, C. (1984). Identité sociale et conscience - Introduction à l'égo-écologie. Montréal: Les Presses de l'Université de Montréal.

Wilson, A. (2014). Being a practitioner: an application of Heidegger's phenomenology. Nurse Researcher, 21(6), 28-33. https://doi.org/10.7748/nr.21.6.28.e1251 